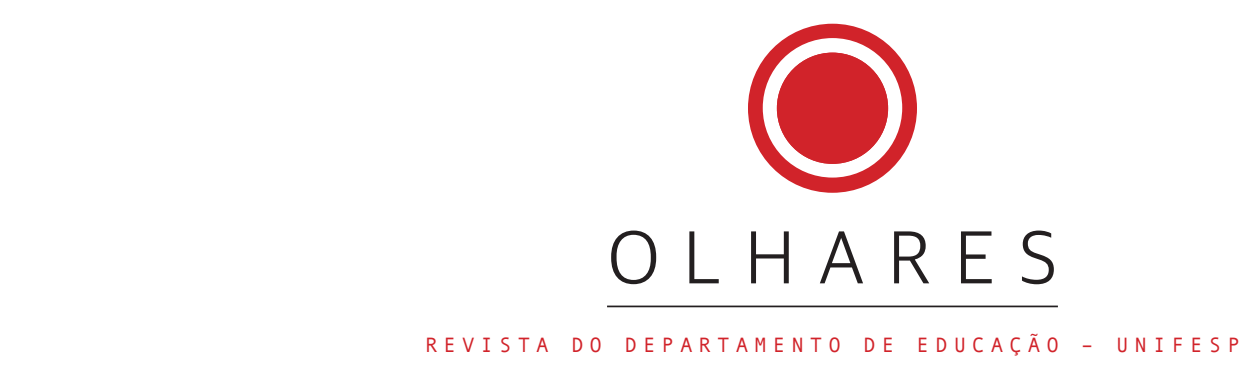

\title{
O manejo de recursos audiovisuais na socioeducação
}

\author{
Daniel Péricles Arruda \\ Professor da Universidade Federal de São Paulo (Unifesp), \\ campus Baixada Santista. \\ pericles.daniel@unifesp.br
}

\section{RESUMO}

Este artigo apresenta algumas reflexões referentes à utilização de recursos audiovisuais no trabaIho em grupo, em especial, com adolescentes em cumprimento de medidas socioeducativas, bem como com suas respectivas famílias. A base deste artigo foram os encontros de formação realizados com a equipe técnica e os educadores do Centro de Atendimento Socioeducativo (Case) da Fundação Criança de São Bernardo do Campo / São Paulo. Considerando a importante relação entre teoria e prática, pode-se perceber que o manejo dos recursos audiovisuais e os objetivos do trabalho em grupo são pontos primordiais para o alcance das finalidades traçadas na socioeducação.

Palavras-chave: Adolescente; Recurso Audiovisual; Socioeducação.

\section{The management of audiovisual tools in juvenile correctional education}

\begin{abstract}
This article presents some reflections regarding the use of audiovisual tools in group work, especially with adolescents who are subjected to correctional education, as well as their respective families. The basis for this article were the training meetings held with the technical staff and educators of the Socio-Educational Assistance Center (Case) of the Children's Foundation of São Bernardo do Campo (Centro de Atendimento Socioeducativo (Case) da Fundação Criança de São Bernardo do Campo), São Paulo. Considering the important relationship between theory and practice, it may be seen that the management of audiovisual tools and the objectives of group work are fundamental points for achieving the purposes set in correctional education.
\end{abstract}

Keywords: Adolescents; Audiovisual Tools; Correctional Education. 


\section{Introdução}

O presente artigo foi elaborado a partir dos encontros de formação realizados com técnicos e educadores do Centro de Atendimento Socioeducativo (Case) da Fundação Criança de São Bernardo do Campo (SP) e com demais profissionais convidados pela instituição. O objetivo dos encontros foi discutir o manejo de recursos audiovisuais no trabalho com adolescentes em cumprimento de medida socioeducativa em meio aberto (Prestação de Serviço à Comunidade e Liberdade Assistida) e seus respectivos familiares. A formação aprofundou a discussão sobre o aprimoramento dos procedimentos metodológicos construídos a partir do uso de filmes, documentários e músicas.

A finalidade deste artigo é apresentar os aspectos mais relevantes - com base na relação entre teoria e prática - para profissionais da área da socioeducação, compreendendo que mesmo sendo embasadas em uma área de atuação específica (adolescente em cumprimento de medida socioeducativa em meio aberto), as reflexões também são essenciais para as demais práticas de socioeducação em diferentes serviços e nas diversas áreas e abordagens profissionais.

\section{Por onde começar o trabalho em grupo?}

Toda vida social é essencialmente prática. Todos os mistérios que conduzem ao misticismo encontram sua solução racional na práxis humana e na compreensão dessa práxis.

Karl Marx e Friedrich Engels, VIII Tese sobre Feuerbach

Por onde começar o trabalho em grupo? Às vezes, na socioeducação, essa pergunta é feita, nem sempre de forma reflexiva, quando na verdade as atividades já começaram. Da mesma maneira em que quando se procura um endereço e se pergunta para alguém na rua "Onde fica este lugar?", a pessoa, por vezes, responde: "Você já passou!” ou, então: "É aqui! Você já está no endereço que procura". Nesse sentido, a questão de "por onde começar" talvez precise ser complementada, com mais possibilidades, pela expressão "por onde não começar?".

Às vezes, não temos o ponto de partida exato ou definido. Há ações que partem de uma demanda apresentada pelo outro, ou são atividades que têm a perspectiva de intervenção proposta pelo profissional. Qualquer que seja a origem, cabe analisar o processo que exige tal intervenção e garantir que as ações a desenvolver tenham objetivos claros e condizentes com a realidade, considerando, inclusive, que na socioeducação a criatividade colabora para ações inovadoras, envolventes e reflexivas. Mas mesmo assim, devem ser consideradas as dúvidas e/ou os questionamentos surgidos nesse percurso, bem como que nem sempre há respostas para tudo o tempo todo. Porém, isso não significa o fim do trabalho e que não se pode fazer mais nada. O não saber, aqui, é compreendido como espaço a ser pensado, construído.

Cabe dizer que nem todas as respostas são dadas, ou contêm a resolução das dúvidas, assim como nem toda pergunta é sinal de dúvida: pode ser também sinal de cuidado, de busca de compreensão, de canal de diálogo e envolvimento. Nem todo questionamento traz consigo um sinal de interrogação ao final da frase, ou seja, é possível identificar perguntas em muitas afirmações e/ou exclamações, considerando o contexto da linguagem e o cenário relacional. 
Nessa lógica, indagar é primordial, mas não somente como um investigador que quer descobrir alguma coisa escondida ou algo não compreendido. Perguntas e respostas, quando promovem a luta de braço, eximem-se do diálogo. A indagação aqui é para livrar-se daquilo que esconde as coisas simples, que esconde o sujeito por meio de um preconceito, que esconde o como fazer. É para livrar-se do metodologismo. Para isso, é necessário, dentre várias categorias, ter sensibilidade e criatividade para reconhecer quais metodologias, técnicas e estratégias são mais pertinentes para servir de mediação no trabalho em grupo.

Para isso há recursos audiovisuais importantes a serem utilizados e, até mesmo, revistos, segundo a avaliação das ações realizadas com grupos de sujeitos. Preconiza-se que a instrumentação de recursos audiovisuais (filmes, documentários, músicas, videoclipes etc.) seja tomada como mediação no processo de trabalho com/em grupos, considerando, inclusive, que tais recursos não são pontos de chegada, mas caminhos para a passagem de conteúdos, valores e intencionalidades traçadas e identificadas pelo profissional responsável.

\section{A socioeducação apregoa um caminho criativo}

...Caminante no hay camino, Se hace camino al andar...

Antônio Machado

A socioeducação - compreendida aqui na perspectiva das medidas socioeducativas preconizadas pelo Estatuto da Criança e do Adolescente (ECA) (BRASIL, 1990) - é uma atividade construída e construtora, da qual participam educador e educando. Construída, por um lado, por exigir do educador ${ }^{1}$ habilidade, conhecimento, prazer, reflexão e crítica e, por outro, por demandar do educando interesse pelas atividades, vontade de participar e capacidade de desenvolver-se no trabalho em questão. Construtora por possibilitar o crescimento dos sujeitos envolvidos e por ser uma prática educativa que considera várias temáticas e ações. A perspectiva construtora baseia-se na capacidade de o adolescente desenvolver-se a partir dos conteúdos e processos socioeducativos, sejam eles relacionados ao autocuidado, sejam eles relacionados ao trabalho, à escola, às convivências institucional, familiar e comunitária, entre outros. Esse processo não é simples e nem fácil, pois

[...] a educação nem sempre é um caminho suave. Ao contrário, principalmente tratando-se de educandos em situação de risco pessoal e social, o processo muitas vezes é árduo, pesado, doloroso e difícil. A tensão, o risco, a angústia nem sempre podem ser evitados pelo educador, pois são parte da essência desse tipo de trabalho. (COSTA, 1990, p. 58)

1 Utiliza-se, neste artigo, o termo "educador" para fazer referência aos técnicos (psicólogos, assistentes sociais, pedagogos etc.) e também aos próprios educadores, bem como o termo "educando" para referir-se aos adolescentes e seus familiares. 
O educador deve perceber as mudanças no percurso socioeducativo e elaborar formas de trabalhá-las, valorizando os detalhes emergentes da relação com o educando e analisando essa experiência com crítica e não a partir de valores pessoais e/ou preconceitos. O educador não é isento das transformações ocorridas no processo de socioeducação, ou seja, se observar bem, é possível identificar que, ao trabalhar com o outro, o educador também se trabalha, se vê em situações limite ou em contextos de superação; cria estratégias de intervenção ou se vê sem "saber o que fazer"; se vê também amadurecendo e se transformando ao contribuir para a socioeducação do outro. Nesse sentido, educador e educando fazem parte de ambas as perspectivas: a construída e a construtora, porém com papéis diferentes e complexos, ou seja,

[...] entre educador e adolescente é construída uma situação de inter-relação dialética de reciprocidade, na qual não apenas o educador reflete sobre a conduta do jovem, mas também o jovem analisa o modo de se relacionar do educador. A construção desse vínculo é fundamental para que o educador se torne um referencial positivo, para que seja uma figura significativa, de confiança do adolescente. (BAPTISTA, 2000, p. 88)

As mediações são necessárias para construir e manter o vínculo entre educador e educando. Há mediações do campo relacional importantes para esse processo, como o diálogo, a solidariedade, o respeito etc., mas destacam-se, neste artigo, as mediações de ordem técnica, que demandam instrumentação, por exemplo, o uso de recursos audiovisuais. Esses recursos são de suma importância para mediar o trabalho socioeducativo e possibilitar outras formas de apreensão e exposição das temáticas em questão. Mas o que é recurso audiovisual?

O recurso audiovisual é um apoio instrucional no processo de comunicação, que sistematiza, a partir de expressões audíveis e visuais, a temática em discussão, pondo em foco as questões a destacar em relação a determinado tema.

De acordo com o Decreto 57.125/1965 (BRASIL, 1965²), em seu artigo 2, "[...] entende-se por 'obra audiovisual' toda obra que consista numa série de imagens fixas ligadas entre si, acompanhadas ou não de sons, passíveis de tornarem-se visíveis e, caso sejam acompanhadas de sons, passíveis de tornarem-se audíveis".

Em outras palavras:

[...] a obra audiovisual é uma produção cultural, no sentido de que há uma codificação da realidade, na qual são utilizados símbolos fornecidos pela cultura, e partilhados por um grupo de pessoas que produz a obra e pelas pessoas para as quais a obra se destina. (ROSA, 2000, p. 35-36)

A utilização de recursos audiovisuais não é prática simples. E nem pode sê-lo, pois envolve uma série de peculiaridades como a linguagem, a cultura, a relação entre educador e educando (relação entre sujeitos e não como sujeito e objeto), significados e sentidos da atividade em pauta e os cuidados para que o educando compreenda a atividade realizada, o conhecimento do grupo envolvido para não expor o educando ao trabalhar algum tema, e a capacidade de construir possíveis caminhos no afã de superar os limites e as limitações das diversas situações, espontâneas ou não.

2 Promulgado na Convenção Internacional para Proteção aos Artistas Intérpretes ou Executantes, aos Produtores de Fonogramas e aos Organismos de Radiodifusão, firmada em Roma, em 26 de outubro de 1961. 
Nessa ótica, todo e qualquer recurso audiovisual demanda instrumentalização e instrumentalidade: instrumentalização enquanto sistematização e conhecimento dos instrumentais, instrumentalidade enquanto desenvolvimento das práticas por meio do aperfeiçoamento das habilidades. Esses dois aspectos não são únicos nessa abordagem sistematizada, porém primordiais para que o trabalho não termine no ponto em que começa ou, até mesmo, para que não deixe de ser começado. Esses movimentos são forças propulsoras que, em atenção, contribuem para a identificação das pegadas emergentes para a construção da metodologia do trabalho, e é nessa realidade que se pode verificar a validade do manejo dos recursos de trabalho com o educando.

\section{Nem as receitas garantem o êxito}

As coisas em geral não são tão fáceis de apreender e dizer como normalmente nos querem levar a acreditar; a maioria dos acontecimentos é indizível,

realiza-se em um espaço que nunca uma palavra penetrou, e mais indizível do que todos os acontecimentos são as obras de arte, existências misteriosas, cuja vida perdura ao lado da nossa, que passa.

Rilke

Como obter sucesso na socioeducação desenvolvendo atividades com o emprego de recursos audiovisuais? Isso parece até título de livro. Mas, infelizmente, não se tem uma solução fechada e nem se pretende ter; porém, há um problema para oferecer-Ihes: Qual é a certeza de que as receitas garantem o êxito? Receitas são possibilidades. Por exemplo, você pode resolver fazer um bolo ao terminar de ler este artigo. Mas o fará pela primeira vez e acompanhando a receita descrita no verso da embalagem da mistura. Você lê atentamente, mede corretamente os ingredientes: coloca a quantidade certa de ovos, acrescenta o leite e o óleo de acordo com a embalagem. Mistura, segue todos os procedimentos, coloca na fôrma e a coloca no forno na temperatura certa, espera o tempo indicado pelo fabricante e, ao apreciar o bolo, constata que ele não ficou bom.

Então, o que faltou? O risco de aplicar uma receita é que não são consideradas as circunstâncias nas quais aquela ação de fato se desenvolveu (qualidade dos ingredientes, condições do clima, o calor liberado pelo forno etc.). O risco das receitas está aí, quando se faz tudo seguindo as indicações e, mesmo assim, não dá certo. Receitas alimentam a comodidade, dão a sensação da certeza ou a própria certeza. Receitas não exigem reflexão, nem leitura da realidade, apenas a leitura de ações com programação metódica.

Como embasamento de atividades que utilizam recursos audiovisuais, a construção de receitas não é aconselhável no trabalho com sujeitos, mas, sim, a construção de referências e metodologias que se apropriam de tais recursos para a sua realização. A metodologia pode ser apoiada por um projeto de intervenção para sistematizar as ações, mas não é apenas um "estudo do caminho para...", e sim também uma construção em processo, coletiva, dialógica, flexível e sensível, que possibilita a crítica e a autocrítica do "caminho para...".

Geralmente, as metodologias revelam-se por expressões simples e explicativas de sua estética. Assim, não há metodologia sem técnicas e instrumentos e serão a importância e o valor 
atribuídos pelo educando a esse modo de trabalhar que validarão ou não a eficiência e eficácia da metodologia.

Portanto, para o desenvolvimento de metodologias e a análise e a sistematização de práticas na socioeducação, encaminha-se o leitor para refletir sobre as indagações operativas e seus significados, no processo de planejamento da ação, expressos a seguir:

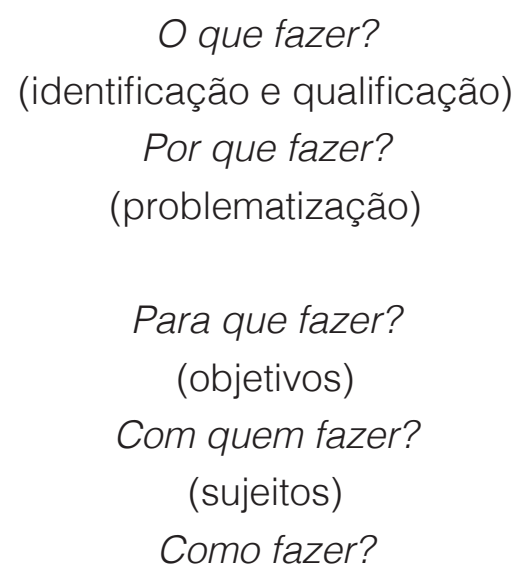

(procedimentos e provimentos dos recursos necessários para a ação)

Quem deve fazer?

(educador, referência etc.)

Quando fazer?

(cronograma)

Onde fazer?

(local e condições do local)

Quanto tempo para fazer?

(disponibilidade e prazo)

O que não fazer?

(crítica e autocrítica)

Como foi feito?

(avaliação permanente e avaliação final)

Como poderá ser feito melhor?

(retomada da ação após cada avaliação)

\section{Como fazer? - pergunta ineliminável e necessária}

La realidad no puede ser modificada, sino cuando el hombre descubre que es modificable y que él puede hacerlo.

Paulo Freire

Como fazer? Apreende-se essa indagação de duas maneiras. A primeira tem por referência a "socioeducação nominal", ou seja, a socioeducação que não alcança e/ou que não objetiva verdadeiramente uma educação para a vida em sociedade: é vazia de conteúdo e plena de ações 
que ocupam o tempo, sem perspectiva ética ou social. Nela, o "como fazer?" almeja receitas. A segunda, ao contrário, visa a uma "socioeducação para além do capital" - parafraseando Mészáros (2008) -, o "como fazer?" não tem medo de falar sobre as dificuldades, nem de buscar alternativas criativas e criadoras. Nessa relação, percebe-se, de um lado, o praticismo (metodologismo) e, de outro, o desenvolvimento da capacidade de manter um relacionamento social positivo e ético.

Nesse praticismo, percebe-se também a banalização da teoria, como se a teoria estivesse na contramão da socioeducação. E no desenvolvimento das capacidades veem-se o reconhecimento, o diálogo e as ações que não separam a teoria da prática. De acordo com Baptista e Battini (2009, p. 29; grifo das autoras), "[...] a teoria é chave explicativa que permite formular o esquema de análise e instrumentar o diálogo do profissional com a realidade". Desse modo, sem a teoria e separando-a da prática, é como procurar por uma ponte já estando nela: quebrando-a com o pensamento é que se vai encontrá-la.

No exemplo, o educador pode deixar de considerar as mediações que "[...] são instâncias de passagem da teoria para a prática, são vias de penetração nas tramas constitutivas do real" (MARTINELLI, 1993, p. 136). A desconsideração possibilita a construção de "abismos" na prática profissional. Isto é, a ideia de uma ação socioeducativa pode ser boa, mas sem as mediações necessárias para a materialização dos objetivos, a ideia não passa de uma boa ideia.

Em muitas situações, o "como fazer?" apresenta-se como um pedido de ajuda ou um grito de socorro. A busca, nesse caso, é por uma resposta conclusiva. Assim, se alguma resposta for encontrada e alcançar assertividade em sua implementação, há forte tendência de acreditar que aquilo que deu certo para uma pessoa, naturalmente dará certo para todos. E esse é um equívoco! Não que seja necessária uma metodologia para cada pessoa, mas todos os sujeitos a serem trabalhados precisam ser alcançados pela metodologia utilizada. Isso implica a capacidade de reconhecer a singularidade e a universalidade do grupo. E também a capacidade de dialogar com a questão de "como fazer?" em vez de temê-la.

O medo talvez caracterize a busca por uma resposta exata para uma complexidade contínua e inacabável que é a vida humana em suas mais diversas relações. Só podemos fazer algo se tivermos as condições adequadas. Há situações em que não é uma exigência máxima saber fazer algo, mas aprender a fazer. Isso não significa o "aprender fazendo" que parece não considerar as condições mínimas, com um mínimo de conhecimento antecipado e a identificação de quem o faz. Essa prática do "aprender fazendo" pode dar certo, como pode dar muito errado. E torna-se uma alternativa à ausência técnica ou do técnico. Sim, os movimentos de ensinar e aprender são indissociáveis - mas são fases diferentes e demandam cuidados.

Um ponto importante é conhecer as práticas metodológicas já existentes, que podem contribuir para a realização do trabalho, bem como para a concretização das aspirações do desenvolvimento metodológico, para a emersão de criatividades e o planejamento das ações.

A título de exemplo, temos as referências metodológicas elaboradas por Myrian Veras Baptista (na área do planejamento social); por Paulo Freire e Roberto Carlos Ramos (na área da educação); por Herbert José de Souza, o Betinho (na área dos movimentos populares); por Jacob Levy Moreno (na área da psicologia); e por Augusto Boal (na área da arte). Todas essas modalidades apresentam um modo de fazer diferente, um modo de fazer flexível, inovador e criativo. Esses modos de fazer reconhecem o outro, a sua cotidianidade, questão inacabável. 
Baptista (2013, p. 13) traz como uma de suas epígrafes a seguinte frase de John Friedmann: "Somos todos planejadores e talvez seja mais importante raciocinar como um planejador que produzir planos acabados". Para essa autora, o planejamento baseia-se na escolha das ações pertinentes para o atendimento de determinadas questões e seus inter-relacionamentos; tem a ver com a reflexão, com a capacidade de tomar decisões, com a ação e a retomada da reflexão dessa operacionalização.

Nesse sentido, para Baptista (2013), o planejamento como processo técnico-político está inscrito numa relação de poder, na medida em que a decisão de efetivar o planejado cabe a quem tem esse poder decisório. O planejador deve, ainda, ter o cuidado de reconhecer que a efetivação do planejado frequentemente dependerá de como o planejador responde aos desafios, à necessidade de estabelecer instituições parceiras, de equacionar as questões políticas, de apreender os interesses congruentes que fazem parte dessa realidade, ou seja:

O planejamento realiza-se a partir de um processo de aproximações, que tem como centro de interesse a situação delimitada como objeto de intervenção. Essas aproximações consubstanciam o método e ocorrem em todos os tipos e níveis de planejamento. Ainda que submetidas ao movimento mais amplo da sociedade, o seu conteúdo específico dependerá da estrutura e das circunstâncias particulares de cada situação. (BAPTISTA, 2013, p. 27)

Por ser o planejamento um processo de aproximação, o estudo da situação a ser trabalhada é quesito importante para identificar as prioridades e para a análise e construção de alternativas.

\section{Conclusões}

Após essas reflexões acerca do uso de recursos audiovisuais, afirma-se que o "como fazer?" é uma questão necessária para que o educador possa contribuir na construção e manutenção de valores com o sujeito, e para que esse sujeito, assim como o educador, tenha os instrumentos necessários para o processo socioeducativo. Considera-se um movimento relevante que o educador consiga alcançar por meio do "como fazer?", o "fazer como". O "fazer como" significa construir um caminho diferente, com pessoas diferentes, apesar de suas diferenças!

Assim, o manejo dos recursos audiovisuais é o andaime no processo de trabalho em socioeducação. A escolha de uma obra audiovisual não deve ser feita por opção pessoal do profissional, mas a partir de um contexto e considerando as suas intencionalidades e identificando aquilo que mais pode tocar e envolver o outro. Uma estratégia interessante, conforme as relações e condições do grupo, é trabalhar as produções dos próprios educandos, ou desenvolver uma oficina temática com a finalidade de produzir o material audiovisual.

Dessa forma, o recurso audiovisual, apoiado em conteúdos consistentes que serão trabaIhados, possibilita o deslocamento, oferece outra forma de enxergar melhor a vida cotidiana e a sua própria vida (HELLER, 1972), ou seja, coloca o sujeito em outro campo do pensar, ao apresentar novas formas de realizar associações. Essas questões são relevantes em socioeducação, inclusive por relacionarem-se ao aprendizado de valores humanos, ao desenvolvimento da consciência crítica e à ampliação da capacidade de compreensão da realidade. 


\section{Referências}

BAPTISTA, M. V. Planejamento social: intencionalidade e instrumentação. 3.ed. São Paulo: Veras, 2013.

Medidas socioeducativas em meio aberto e de semiliberdade [não publicado]. São Paulo: Febem, 2000.

BAPTISTA, M. V.; BATTINI, O. A prática profissional do assistente social: teoria, ação, construção do conhecimento. São Paulo: Veras, 2009.

BRASIL. Decreto 57.125, de 19 de outubro de 1965. Promulga a Convenção Internacional para Proteção aos Artistas Intérpretes ou Executantes, aos Produtores de Fonogramas e aos Organismos de Radiodifusão. Diário Oficial da União, Brasília, 28 out. 1965.

. Lei n. 8.069, de 13 de julho de 1990. Dispõe sobre o Estatuto da Criança e do Adolescente e dá outras providências. Diário Oficial da União, Brasília, 16 jul. 1990.

COSTA, A. C. G. da. Trabalho com infratores: uma ciência árdua e sutil. In: lescência, pobreza: temas de um Brasil menor. São Paulo: Fundap, 1990. Infância, ado-

FREIRE, P. Concientización: teoría y práctica de la liberación. Buenos Aires: Búsqueda, 1974. HELLER, A. O cotidiano e a história. Rio de Janeiro: Paz e Terra, 1972.

MARTINELLI, M. L. Notas sobre mediações: alguns elementos para sistematização da reflexão sobre o tema. Revista Serviço Social \& Sociedade, n. 43, São Paulo: Cortez, 1993.

MARX, K.; FRIEDRICH, E. A ideologia alemã. 3.ed. São Paulo: Martins Fontes, 2007.

MÉSZÁROS, I. A educação para além do capital. 2.ed. São Paulo: Boitempo, 2008.

RILKE, R. M. Cartas a um jovem poeta. Porto Alegre: L\&PM, 2009.

ROSA, P. R. da S. O uso dos recursos audiovisuais e o ensino de ciências. Cad. Cat. Ens. Fís. v. 17, n. 1, p. 33-49, abr. 2000. Disponível em: <https://periodicos.ufsc.br/index.php/fisica/article/ view/6784/6249>. Acesso em: 20 jun. 2017.

Recebido em: 08/03/2019

Aceito em: 30/07/2019 